\title{
Access Needs: Centering Students and Disrupting Ableist Norms in STEM
}

Daniel L. Reinholz** and Samantha W. Ridgway*

'Department of Mathematics and Statistics, San Diego State University, San Diego, CA 92182-7720; ${ }^{\ddagger}$ Center for Research in Mathematics and Science Education, San Diego State University,

San Diego, CA 92120-5013

\begin{abstract}
This essay describes the concept of access needs as a tool for improving accessibility in science, technology, engineering, and mathematics (STEM) education broadly, from the classroom, to research group meetings, to professional conferences. The normalization of stating access needs and creating access check-ins is a regular practice used in disability justice activist circles, but it has not yet been normalized in STEM education spaces. Just as normalizing the use of pronouns has been an important step for supporting gender justice, we argue that normalizing access talk is an important step for advancing disability justice in STEM fields. Moreover, we argue that all individuals have access needs, regardless of whether they are disabled or nondisabled. We provide concrete suggestions and techniques that STEM educators can use today.
\end{abstract}

\section{INTRODUCTION}

My name is Ricardo, my pronouns are he/him, and I need to have all course materials in plain text for my text-to-speech software. My name is Emile, my pronouns are she/ her, and it is important for me to have regular, short breaks in our meetings. My name is Alex, my pronouns are they/them, and my access needs are currently being met.

While exchanges like the above are commonplace in disability justice activist spaces, they are seldom a part of conversations in science, technology, engineering, and mathematics (STEM) education. Providing one's name and pronouns upon introduction is becoming a standard practice, but discussions about accessibility are still rare. We argue that this is a problem for both disabled and nondisabled students, staff, and faculty in the academy. This essay provides an introduction to disability justice and the concept of access needs and access check-ins and presents simple, concrete suggestions for normalizing access talk and disrupting ableism in academic spaces. This essay is framed by our experiences as two disabled scholars in STEM education.

\section{BACKGROUND}

Disability and STEM Education

Despite increasing attention to equity in postsecondary STEM education (e.g., President's Council of Advisors on Science and Technology, 2012), equity is rarely conceptualized with adequate attention to access. Disability is generally positioned after the "and" in phrases like "inequities based on race, gender, and disability" (Slaton, 2013). Often, disability is not investigated at all, or when it is, the way research is framed can actually perpetuate harm toward and misconceptions about disabled students. ${ }^{1}$ For example, a recent review of disability-focused work in

${ }^{1}$ The term "disabled students" is used rather than "students with disabilities" to "forefront power imbalances inherent in constructing and identifying disability" (Padilla and Tan, 2019, p. 316) and to forefront that disability is socially constructed.
Cynthia Bauerle, Monitoring Editor Submitted Jan 22, 2021; Revised Jun 23, 2021; Accepted Jul 8, 2021

CBE Life Sci Educ September 1, 2021 20:es8 DOI:10.1187/cbe.21-01-0017

*Address correspondence to: Daniel L Reinholz (daniel.reinholz@sdsu.edu).

(C) 2021 D. L. Reinholz and S. W. Ridgway. CBE-Life Sciences Education (c) 2021 The American Society for Cell Biology. This article is distributed by The American Society for Cell Biology under license from the author(s). It is available to the public under an Attribution-Noncommercial-Share Alike 3.0 Unported Creative Commons License (http://creativecommons.org/ licenses/by-nc-sa/3.0).

"ASCB®" and "The American Society for Cell Biology ${ }^{\circledR}$ " are registered trademarks of The American Society for Cell Biology. 
mathematics education revealed that much of the research framed disabled students as a "problem" to be solved and focused only superficially on student sense-making (Lambert and Tan, 2017). In this way, the stigma associated with disability can be a marginalizing factor in itself, even in efforts that are ostensibly designed to help disabled students (Artiles, 2019; Mueller, 2021). Because such work is grounded in a deficit view of disabled students, it obscures their unique strengths (Fox et al., 2019; Chiang, 2020).

The current approach to working with disabled students in STEM higher education can be traced to the disability rights movement. Building on momentum from the civil rights movement in the 1960s, disability rights activists built a cross-disability coalition that used protest and public actions to pass legislation. Most notable was the landmark Americans with Disabilities Act (ADA; Batavia and Schriner, 2001). The ADA, as well as its predecessor (Section 504 of the Rehabilitation Act of 1973), prohibits discrimination based on disability and legally mandates that institutions provide reasonable accommodations for disabled people. The systems of support that exist on college campuses today are largely a product of this legislation (Gin et al., 2020). But what constitutes a reasonable accommodation in the context of STEM education?

Research laboratories-an icon of the sciences-are often inaccessible, featuring specialized equipment, requiring long work hours, and having nonergonomic workstation designs (Riley, 2013). Similarly, an overemphasis on the visual, analytic, and abstract in STEM can marginalize disabled people who would be better able to use visual or audio representations (Slaton, 2013). Access issues may be further exacerbated for Deaf populations, given that the technical language used in the STEM fields largely does not exist in the standard vocabulary of American Sign Language (ASL). As a result, ASL interpreters must first become fluent with STEM concepts and then develop specialized signs to represent complex disciplinary concepts (Andrei et al., 2013). This formidable challenge is further exacerbated when students deal with lack of continuity in interpreters, so that systems of communicating need to be developed again and again.

In many ways, the concept of reasonable accommodation is overly vague and does little to guarantee that students actually get what they need. Within the STEM higher education landscape, the onus to secure appropriate accommodations lies almost entirely with individual students. Such students may not know what accommodations are available or how to get them. Some students who would qualify for accommodations may not even identify as disabled. In this way, the stigma associated with disability can serve as a barrier to support. The result is that students with more resources and capacity to engage in self-advocacy are ultimately the ones who are best served by the current system (Pfeifer et al., 2020). In this way, the accommodations model can further exacerbate inequities within the disability community.

In addition to the access issues that have existed for decades in traditional STEM learning environments, some issues are made worse by the adoption of active-learning techniques. For example, the complexities of social interactions within small groups can further exacerbate the lack of access that existed in lectures (Gin et al., 2020). Just as active learning without attention to equity can actually further marginalize gendered and racially minoritized students (Ernest et al., 2019; Shah et al., 2020), active learning without attention to access and equity for disabled students can similarly have negative consequences. To truly make progress toward a STEM education that is meaningful for disabled students, it is necessary to reframe how disability is conceptualized (Mueller, 2021).

\section{Disability as a Structural Issue}

The accommodations approach is grounded in the medical model of disability, which focuses on providing "supports" for what disabled people supposedly lack (Triano, 2000). In contrast, the social model of disability focuses on the structural barriers within society that prevent disabled people from fully participating (Oliver, 2013). ${ }^{2}$ The social model problematizes the idea of a normal body or mind, instead emphasizing the alignment between particular bodies and the external environment. When appropriate accommodations are made (e.g., wheelchair access, live captioning) it can help remove barriers in society that effectively disable some people and not others.

Just as scholarship on racial inequity highlights that racism is a systemic, structural, and societal issue (Bonilla-Silva, 2003), a social model of disability helps draw attention to how ableism is a structural issue, not simply a matter of interpersonal interactions. For example, ableism creates oppressive societal discourses in which disabled people are pathologized (Barnes, 1995; Gernsbacher, 2017). In these discourses, terms like "handicapped," "retarded," or "crazy" are also used to denigrate nondisabled people, by associating them with the negative stigma of disability. Ableist stereotypes and tropes provide barriers for disabled people to fully participate in schooling and society, because they are never seen as "normal enough" and instead are subject to discrimination and exclusion (Barnes, 1995; Cheng and Beigi, 2011).

\section{Disability Justice}

The disability justice movement picks up where disability rights left off. Disability justice focuses on liberation for disabled people, with particular attention to how disability intersects with other identities such as race, gender, and sexuality (Sins Invalid, 2019). Although the disability justice movement centers disability, it focuses on justice and liberation for all diverse people, and thus has important implications even for nondisabled people. Disability justice contests the notion of a normal or normative ideal, working toward collective liberation for all oppressed people. The aims of the movement can be summarized through 10 core principles (see Table 1; Sins Invalid, 2019).

The disability justice movement views ableism as closely intertwined with other systems of oppression such as anti-Blackness, misogyny, colonialism, and capitalism (Lewis, 2021). For example, historically, ableism was used to justify enslavement (Baynton, 2001) and eugenics (Stoskopf, 2002), by labeling racially minoritized people as disabled and defective as a

\footnotetext{
${ }^{2}$ Modern scholarship in disability studies tends to emphasize both the individual and social dimensions, and thus may draw upon both aspects of the medical and social models (Jarman et al., 2017). The extent to which disabled people identify with one perspective over the other depends heavily on the nature of their disabilities. For example, people with chronic illnesses may identify more with a medical model and wish for those illnesses to be cured. In contrast, Deaf or Autistic communities may more openly celebrate their unique cultures and have no desire to conform to a normative standard (e.g., Bauman and Murray, 2009).
} 
TABLE 1. Ten principles for disability justice, paraphrased from Sins Invalid (2019)

\begin{tabular}{|c|c|}
\hline Principle & Description \\
\hline Intersectionality & $\begin{array}{l}\text { Intersectionality focuses on the multitude of identities that disabled people have, including their race, class, } \\
\text { gender, sexuality, age, and religious background. To understand the experiences of disabled people, the } \\
\text { interplay of these many identities must be considered. }\end{array}$ \\
\hline $\begin{array}{l}\text { Leadership of those most } \\
\text { impacted }\end{array}$ & $\begin{array}{l}\text { To dismantle systems of oppression, we should focus on the experiences of people who are most impacted by } \\
\text { them, rather than looking to outside experts who have limited lived experiences of being harmed by such } \\
\text { systems. }\end{array}$ \\
\hline Anti-capitalist politics & $\begin{array}{l}\text { Capitalism is predicated on competition, workaholism, and productivity. These ideals dehumanize all people and } \\
\text { are especially harmful for people with disabled bodyminds who cannot or do not conform to such standards. }\end{array}$ \\
\hline Cross-movement solidarity & $\begin{array}{l}\text { By working in solidarity with other social justice movements, disability justice can help build a united front and } \\
\text { address systemic oppression. }\end{array}$ \\
\hline Recognizing wholeness & $\begin{array}{l}\text { Nobody is "just disabled." Disabled people are whole people with their own histories and life experiences. They } \\
\text { have their own internal experiences consisting of thoughts, sensations, emotions, perceptions, and fantasies. }\end{array}$ \\
\hline Sustainability & $\begin{array}{l}\text { Disability justice resists a false sense of urgency, instead moving at the pace of humanity in a way that is } \\
\text { sustainable and promotes self and collective care. }\end{array}$ \\
\hline $\begin{array}{l}\text { Commitment to cross-disability } \\
\text { solidarity }\end{array}$ & $\begin{array}{l}\text { All disabled people are valid and valuable. Disability justice aims to dismantle hierarchies in the disability } \\
\text { community and in the world. }\end{array}$ \\
\hline Interdependence & $\begin{array}{l}\text { Rejecting colonial notions of independence, disability justice dreams of a future when people can interde- } \\
\text { pendently meet their needs in harmony with the planet. }\end{array}$ \\
\hline Collective access & $\begin{array}{l}\text { All people function differently depending on the context and environment. All people have access needs, and } \\
\text { meeting them is a collective responsibility. }\end{array}$ \\
\hline Collective liberation & $\begin{array}{l}\text { Collective liberation recognizes the uniqueness of all bodyminds and their intersectional identities. A vision for } \\
\text { liberation can leave no body or mind behind. }\end{array}$ \\
\hline
\end{tabular}

justification for mistreatment. Similar labeling happens in today's schools, marginalizing racially minoritized students (Annamma et al., 2013). As the ultimate category of "other," disability is used as a signifier of defectiveness, making it complicit in all other systems of oppression-from white supremacy to misogyny-which also aim to other particular people and place them in hierarchies. Fundamentally, ableism is about labeling, sorting, and categorizing people who are seen as more or less. This is also the primary purpose of race and racism, which create hierarchies to hoard social and economic power (Bonilla-Silva, 2003; Martin, 2009).

Lewis (2021) emphasizes that ableism impacts disabled and nondisabled people alike. Ableism perpetuates the myth of a normalized, ideal body or mind to which all people should conform. In Western societies, this idealization creates immense pressure to be thin, physically strong, independent, and incredibly productive. In the academy, the prevalence of ableism is closely linked to the ideas of meritocracy and workaholism. This assumption of normality also contributes to policies that marginalize women in the academy (National Academy of Sciences, 2007), for instance, when having a child or responsibility for taking care of a child are seen as a deviation from the norm (and societally, these pressures disproportionately fall upon women).

\section{Accessibility and Access Needs}

A core issue at the heart of disability justice is the notion of access. A space can be considered accessible if it provides individuals with everything that they need to fully participate in the space or activity (Sins Invalid, 2019). Commonly, accessibility is thought of in terms of ASL interpretation, wheelchair access, or screen reader compatibility. Other access needs might include an opportunity to stand up and stretch (rather than stay seated for hours at a time), access to gender-neutral restrooms, eating during a meeting, accessible language, breaks between meetings, having participants raise their hands before speaking, or adequate childcare support. Although all people have access needs, they are rarely made explicit in most spaces. In today's society, stating one's access needs is often seen as a sign of weakness and deviation from the normative standard. From our perspective, access is a precursor to equity, and without access, equity is unattainable.

Access needs are closely related to the concept of access intimacy (Mingus, 2017). Mingus describes access intimacy as an "elusive, hard to describe feeling when someone 'gets' your access needs." Mingus continues, by stating that this intimacy is shared with "many other disabled and sick people who have an automatic understanding of access needs out of our shared similar lived experience of the many ways ableism manifests in our lives." Access intimacy is often the most difficult to cultivate between disabled and nondisabled people, given the general lack of awareness that nondisabled people have toward disabled people and the ubiquity of bias and discrimination toward disabled people (Wilson and Scior, 2014).

It is important to establish access intimacy, as access needs cannot simply be assumed. For example, well-meaning and misinformed nondisabled people may attempt to move or physically assist a person with a mobility disability (e.g., in a wheelchair). This is problematic and can be a very traumatic experience when someone is moved against their will. Furthermore, many disabilities are invisible. Simply because someone looks nondisabled, it is not safe to assume that they are nondisabled, when it is estimated that up to $25 \%$ of people in the United States have some form of disability (Centers for Disease Control, 
2020). The academy is full of disabled students, faculty, and staff, but most are invisibilized, given the pressures to conform to normative standards.

We argue, as others have before us (e.g., Mingus, 2017; Sins Invalid, 2019), that normalizing access needs is necessary to disrupt the ableism that is ubiquitous in the academy and in our society. In the ableist status quo, access needs are typically considered as a nuisance or, at best, are an afterthought. In a capitalist system, providing for access is often seen as an extra and unnecessary cost. Even in work that is ostensibly about equity and social justice, access and disability are minimized. To be clear, disability justice requires much more than just creating access or providing accommodations. Collective access is simply a first step on the long journey toward collective liberation. Below, we offer concrete suggestions on how to normalize access talk, increase access check-ins, and disrupt ableism.

\section{AUTHOR POSITIONALITY}

The authors are both disabled STEM education scholars, who have numerous examples of experiencing ableism and barriers to access in the academy. ${ }^{3}$ For example, D.L.R. recalls experiences as an undergraduate engineering student and being unable to complete the physical demands required to align lasers in an optics lab. This, in part, led D.L.R. to abandon the pursuit of engineering as a profession and instead pursue mathematics. Today, D.L.R. has a variety of access needs, including frequent breaks, not sitting for extended periods of time at a computer, and protection from illness (being immunocompromised).

S.W.R. recalls experiences of isolation, gaslighting, and jokes at her expense in an established neuroscience laboratory as well as having her disability questioned and being told that she was not able to request reasonable accommodations. S.W.R.'s time was consistently consumed with advocating for accommodations-such as STEM-specialized ASL interpreters-that her time spent working was impeded and she would often have to work upwards of 80 hours per week to complete her tasks. This led to a change in direction from studying neurobiology to studying math and science education. Today, S.W.R still has a variety of access needs, including ASL interpreters, scribes or written notes for meetings, frequent breaks, alternative participation methods for classes, clear and direct communication or instruction, and being able to move around/turn camera off when needed.

We also recognize our privilege as disabled white scholars and aim to use this privilege to open up conversations around disability, racism, and other forms of oppression in STEM education. Access needs often go unmet, and this is especially true for people who are multiply marginalized. The scenarios we

\footnotetext{
${ }^{3}$ The authors personally use identity-first language here (disabled) to emphasize the role of society in producing disablement. We note that the disability community distinguishes between person-first and identity-first language, and there is no proferrered standard; it is a matter of individual preference. Person-first language (e.g., person with disabilities) separates the person from their disability and focuses on their personhood. Such language is currently widespread and typical for many individuals with medical diagnoses or other disorders that are not necessarily tied to culture (Dunn and Andrews, 2015; Flink, 2021). In contrast, identity-first language strongly connects to disability culture in which identity is embedded (e.g., an austic person, rather than "person with autism"). Many cultural disability communities tend to prefer identity-first language, including Deaf, Blind, and Autistic communities, although the preferences may not be universal for all members of these communities.
}

share are based on our own experiences and experiences shared by our colleagues.

\section{ACCESS IN STEM EDUCATION: THREE ENVIRONMENTS}

To illustrate the importance of normalizing conversations about access needs in STEM education, we discuss some of the access issues that can arise in common learning environments. We offer these scenarios to illustrate that lack of student engagement may not necessarily relate to lack of interest but rather to lack of access.

\section{Laboratory Spaces}

The laboratory is an icon of the sciences. It is an important locus of learning and knowledge production. Whether through laboratory classes, or as part of research projects, it is important to construct an accessible environment as a foundation for student engagement. Here we consider some access barriers that can exist.

Ergonomics. Laboratory work usually requires extended engagement. Typically, laboratory classes are scheduled for three or more hours, and research work may consist of months of extended engagements in a lab. Such long sessions may put pressure on students to sit at a computer, a lab bench, or other apparatus for extended periods of time. This is ergonomically problematic for all people and can be especially damaging for people with physical disabilities. For some people, the physical requirements of a space can cause physical harm and may result in irreparable damage to the body.

Bodily Functions. All people need to eat food and drink to function, but in a laboratory environment, food or drink may pose a hazard to people or equipment. Not eating or drinking can cause discomfort for all people but can be especially problematic for students who work long hours (and cannot eat before class), pregnant/breastfeeding students, or students with diabetes or other chronic illnesses. Similarly, in running a long experiment there is intense social pressure to "be present," which may be at odds with taking time to use the restroom. It is important to consider the affordances of a given physical space. For instance, are gender-neutral bathrooms available? And if people will be eating food, does it meet the different dietary requirements for someone based on food allergies or religious beliefs?

Accessible Spaces. Laboratory spaces are not always designed with access in mind. Wheelchair users may not be able to navigate a space. Blind and/or Deaf people may need different types of equipment to engage with an experiment. Even physical tabletops may be too high (or too short) for comfortable, accessible use. With intense pressure for efficiency and competition, it becomes easy to neglect the many ways that a laboratory environment can keep some people out rather than utilize access-centered design.

Considering these access barriers, it is clear that student engagement in a laboratory setting can be heavily mediated by the physical environment. There is often pressure in the sciences to neglect basic human needs (e.g., food and drink) to compete and perform at a higher level. While there are no quick fixes to this particular culture, building in breaks in a laboratory 
class session or setting reasonable limits in a research laboratory can help. Policies around food, drink, and restrooms can also be carefully thought out in a way that students can meet these basic needs. Other accessibility issues may require deeper conversations (and possible innovation) to address. In any case, having conversations about accessibility can normalize such needs, rather than forcing students to try to hide their basic physical needs.

\section{Active-Learning Classrooms}

Active-learning classrooms are a mainstay of STEM education reform efforts and have the potential to support deeper student learning (Freeman et al., 2014). At the same time, the switch to active engagement methods can create a variety of new barriers for disabled (and nondisabled) people (Gin et al., 2020). Here we explore some common access issues.

Small-Group Work. Small groups provide an opportunity for students to explain their thinking and learn from collaborations with peers. At the same time, students-especially those with learning disabilities or mental health issues-may hesitate to share their ideas for fear of judgment. Similarly, someone with autism might struggle to focus within the context of an intensely social and overstimulating small-group environment. Smallgroup interactions can also create access barriers for queer students or students of color, who may experience interpersonal microaggressions (Cooper and Brownell, 2016; Shah et al., 2020).

Required Participation. Given the documented connection between participation and learning (e.g., Banes et al., 2019), it is tempting to implement policies that incentivize or require student participation. Yet such policies can create barriers for students who are chronically ill and may miss a large number of sessions. Autistic or socially anxious students might also feel uncomfortable participating. Similarly, students whose first language is not the language of instruction face barriers to actively participate in a fast-paced classroom. Finally, given the prominence of white masculine participation norms in STEM, women and racially minoritized students may not be given as many meaningful opportunities to participate, as white/Asian men in STEM take up a disproportionate amount of public space (e.g., McAfee, 2014; Ernest et al., 2019).

Assessment Practices. Even in reform-oriented classrooms, bias toward assessment practices perceived as objective-particularly timed exams-may effectively create access barriers. This is a high-pressure stress-inducing practice, especially for students with anxiety or other mental illnesses (Gin et al., 2020). Clicker questions can have a similar effect, as students need to work quickly to arrive at the "correct" answer. Such assessment practices also create access issues for women and racially minoritized students, who have to overcome stereotype threats to succeed (Nguyen and Ryan, 2008).

To be clear, active-learning environments have a lot to offer in terms of improving STEM education. At the same time, they should be viewed critically with regard to potential access and equity issues that can arise, to which instructors need to be attentive. There is nothing "normal" about a typical classroom environment or assessment practices, and in many ways, they do not resemble authentic disciplinary practices. Anytime an instructor aims to create a productive, social learning community, it is necessary to consider the access and equity issues that arise from different abilities, genders, races, and other social identities coming together. Access talk can help draw attention to these differences, so that more effective environments can be created.

\section{Synchronous Virtual Meetings}

Teaching synchronous online courses poses a number of challenges, including students turning their cameras off. Many faculty members can relate to the deflating experience of teaching to a wall of blank boxes. In addition, the lack of paralinguistic (i.e., nonverbal) cues may make it more challenging for other students to interpret one another's contributions (Moorhouse, 2020). For these reasons, a mandated "cameras on" policy may seem appealing. However, it is important to recognize the many potential barriers to access in a synchronous meeting, many of which may result in students turning their cameras off.

Technical Limitations. The most obvious reason that students might have a camera off is because they do not have access to appropriate technology. This could be the result of not having a camera, having insufficient bandwidth for a video call, or having a phone with a broken camera. Given stigma around socioeconomic status and expectations to be able to afford needed technologies, students may not feel safe to volunteer such information.

Home Environment. Students may not wish to turn their cameras on because of the nature of their home environment. For example, parents with young children often experience continuous interruptions to their meetings. People living in a shared space may not want to reveal what is happening in the background. Especially for students who are joining a class from their bedrooms, turning on their camera may feel invasive, as they do not want to invite strangers into their intimate space. This is especially true for survivors of violence and trauma.

Working during Class. Although students are generally assumed to be fully focused during class time, especially during the COVID-19 pandemic, some students might need to take on additional work hours at times they have little control over, which can lead to multitasking, such as working during class.

Of the possible reasons for cameras off listed, ostensibly, none of the above needs are directly related to disability. With awareness of these different issues, a variety of solutions are possible. Some may require structural intervention, like providing monetary resources to ensure that all students have access to required technology. Other interventions may be possible at a classroom level. For instance, using a virtual background could potentially alleviate some of the issues with a home environment or feeling unsafe. Issues like working during class might require a larger adjustment. For some students, an overreliance on synchronous meetings might make a class inaccessible, and therefore the use of a variety of modalities (synchronous and asynchronous) may be necessary. Possible solutions are varied, and without frank conversations about access, instructors can do no better than guess what their students need. 


\section{STRATEGIES FOR NORMALIZING ACCESS TALK}

Here we offer four concrete strategies for normalizing access talk in STEM and creating a space that is more inclusive for all bodies and minds. To support productive talk about access, we argue that a minimum baseline of accessibility should be met from the offset. When teaching any class, lab, or planning a conference or retreat, one can draw upon the many established guidelines that already exist for creating accessible spaces (e.g., Sins Invalid, 2019). In addition, frameworks such as Universal Design for Learning (UDL) provide concrete suggestions for designing accessible learning environments (Rose, 2000; Rose and Meyer, 2002). UDL has three main guidelines that focus on providing multiple means of engagement, representation, and action/expression. When learning environments are designed based on UDL principles, they better meet varied access needs even without accommodations.

Once a minimum baseline of accessibility has been met, it lowers barriers that may prevent others from self-advocating for their own access needs. All people have access needs, and these needs intersect with one's many other identities. Cultural expectations around time, productivity, and so forth are all a part of access. Access needs also depend on gender (e.g., bathrooms), religion (e.g., respecting prayer times), or social class (e.g., the need for childcare). It is critical to recognize one's own identities and privileges when creating spaces for inclusive talk around access. We now turn to four strategies for normalizing access talk.

\section{Introductions}

Featured in the introduction of the essay, an access check-in can be included when people introduce themselves (Sins Invalid, 2019). The introductions would involve people stating their name, pronouns, and access needs (or stating "my access needs are being met"). Until access talk becomes normalized, this will be an unfamiliar practice for most. Accordingly, the use of access check-ins is a perfect place to open up the conversation around access. Before introducing the process, one can talk about what access is, and why it is important for everyone (especially disabled people). As faculty get to know their students by name, pronouns, and access needs, they can create a more humanized social presence in their classroom. This is especially important in STEM, where faculty might not always see the importance of building this type of social presence in their classrooms, or it is assumed to be less important (Reinholz et al., 2020).

At first, it may be necessary to provide individuals with examples of what different access needs may be (the scenarios we presented provide a number of examples). It can also be helpful to start the process by opening up about one's own access needs, whatever they may be. It is also important to avoid having individuals state that "I do not have access needs." All people have access needs, but some people might take it for granted when they are met in many circumstances. Just as cisgender and gender-conforming individuals may use the pronouns that many others would assume, they still do use pronouns. Making talk about pronouns explicit opens space for a more open recognition of the diversity of gender. Talking about access needs is the same, where it concerns disability.

\section{Access Needs Check-In}

It is important to regularly check in around access needs. Simply because needs were being met one day does not mean they can be assumed to be met the next day. Especially for people with chronic illnesses, one day may look very different from the next, or even one hour may look different from the previous hour. A facilitator can build into a meeting or class session regular opportunities to check in about access. This could happen at the beginning of a class session, in the middle of a collaborative group task, or before a break, allowing for adjustments to be made when the break is over. "Are access needs being met?" or "What do you need to do your best work?" are simple questions to open such conversations. Even when getting a group's attention, a facilitator could ask, "Does everyone have access? What do folks need?," rather than saying "Can everyone see or hear me?," which assumes that seeing and hearing are the only means of access. Like the access check-in, asking such a question in a public space normalizes access talk. Especially in STEM learning environments, the day-to-day requirements in terms of technology or laboratory equipment may shift, so regular checkins are needed to adapt to changing circumstances.

\section{Allowing for Flexibility}

Part of meeting access needs requires flexibility. If access needs are not being met, then it must be possible to adjust the course of action so that access can be established. In STEM courses, there is often a great deal of pressure to cover a large amount of material, which can be in direct opposition to making adjustments. As such, instructors need to build in some flexibility from the offset, so that there is room to adjust when needed. Otherwise, if access needs are expressed and then minimized or not met, it diminishes trust and no longer allows for the vulnerability needed to share access needs. It is important to acknowledge that some access needs may not be easy to meet or may be expensive to meet in a capitalist, ableist society. Still, if one is committed to disability justice, then it is important to find a way to meet such needs.

\section{Anonymous Feedback}

These strategies simultaneously elicit information about access needs and normalize access talk. Nonetheless, not all people will feel comfortable or will want to discuss their access needs. For this reason, it can be helpful to allow for private ways to request certain types of access. Private requests are more likely to be received if the above strategies have been used to create an inclusive and accessible space from the offset. Stating one's access needs requires vulnerability, and if there is fear of backlash or being shut down, many people may simply choose not to express their needs. There are a number of ways to solicit anonymous feedback. This could be placed on an "exit ticket" as students leave the class session, through an anonymous poll, through a learning management system, or during the registration for a conference. In addition to supporting improved accessibility, seeking student feedback can also help humanize a STEM learning environment and counteract student perceptions that STEM faculty may not care about them (Seymour and Hewitt, 1997).

\section{DISCUSSION}

Discussions around equity in STEM education are now prevalent. However, in our experiences, talk about disability and 
access is rarely a part of such discussions. Yet, given the close interconnections between ableism and other forms of oppression, promoting disability justice is necessary to truly achieve social justice for any marginalized population. This is especially true when one considers that all demographics have many members who are disabled, and for most people, acquiring a disability sometime in their lives is almost an inevitability.

This essay argues for a particular type of talk around disability, called access talk. The purpose of access talk is to ensure that all individuals have access to a given learning environment, which is the necessary precursor for equity. Moreover, access talk normalizes talk about disability and ableism, which is necessary for dismantling these often-invisible systems of oppression. Normalizing access talk is simple and can be achieved through basic techniques like those we described earlier.

Access needs are many and varied. Discussions around disability commonly focus on physical access, ASL interpretation, and screen reading. These conversations less often include discussions around access needs for individuals who are neurodiverse or chronically ill or have mental illness or other less visible disabilities. In either case, for disabled people, access needs often provide the minimum baseline for what it means to be able to enter and operate within a space.

Even for nondisabled people, talking about access needs can create a more inclusive and humanizing space. Needs may be dietary (e.g., vegetarian, kosher, halal), language-related (e.g., supporting emergent bilinguals, immigrants), text related or concerning readability, or trauma sensitive and trauma informed. While it is not possible to provide an exhaustive list of potential needs here, the most important thing to recognize is that all people have access needs as a part of our humanity and being fully human. This essay focuses primarily on classrooms, but the organizing principles apply as well to a research lab, conference, or institution of higher education.

Normalizing access talk is a necessary and insufficient first step to promoting equity and collective liberation in STEM education. True disability justice requires much more than just providing access for some disabled people into an overarching ableist system. Disability justice requires reimaging and refiguring the academy and broader society into one that is organized around interdependence, harmony, and our own individual humanity. This can only be achieved when the interconnections between ableism and other systems of oppression are made clear and these systems can be dismantled.

\section{ACKNOWLEDGMENTS}

This material is based upon work supported by the National Science Foundation under grant no. 1943146.

\section{REFERENCES}

Andrei, S., Osborne, L., \& Smith, Z. (2013). Designing an American Sign Language avatar for learning computer science concepts for Deaf or hard-of-hearing students and Deaf interpreters. Journal of Educational Multimedia and Hypermedia, 22(3), 229-242.

Annamma, S. A., Connor, D., \& Ferri, B. (2013). Dis/ability critical race studies (DisCrit): Theorizing at the intersections of race and dis/ability. Race Ethnicity and Education, 16(1), 1-31. https://doi.org/10.1080/13613324 .2012.730511

Artiles, A. J. (2019). Fourteenth Annual Brown Lecture in Education Research: Reenvisioning equity research: Disability identification disparities as a case in point. Educational Researcher, 48(6), 325-335. https://doi. org/10.3102/0013189×19871949
Banes, L. C., Restani, R. M., Ambrose, R. C., Martin, H. A., \& Bayley, R. (2019) Relating performance on written assessments to features of mathematics discussion. International Journal of Science and Mathematics Education, 18, 1375-1398. https://doi.org/10.1007/s10763-019-10029-w

Barnes, C. (1995). Disability, cultural representation and language. Critical Public Health, 6(2), 9-20. https://doi.org/10.1080/09581599508409048

Batavia, A. I., \& Schriner, K. (2001). The Americans With Disabilities Act as engine of social change: Models of disability and the potential of a civil rights approach. Policy Studies Journal, 29(4), 690-702. https://doi. org/10.1111/j.1541-0072.2001.tb02122.x

Bauman, H. D., \& Murray, J. (2009). Reframing: From hearing loss to deaf gain. Deaf Studies Digital Journal, 1(1), 1-10.

Baynton, D. (2001). Disability and the justification of inequality in American history. In Longmore, P., \& Umansky, L. (Eds.), The new disability history: American perspectives (pp. 33-57). New York: New York University Press.

Bonilla-Silva, E. (2003). Racism without racists: Color-blind racism and the persistence of racial inequality in the United States. Lanham, MD: Rowman \& Littlefield.

Centers for Disease Control. (2020). Disability impacts all of us. Retrieved January 7, 2021, from www.cdc.gov/ncbddd/disabilityandhealth/ infographic-disability-impacts-all.html\#: : text=61\%20 million $\% 20$ adults\%20in\%20the,have\%20some\%20type\%20of\%20disability

Cheng, K. K. Y., \& Beigi, A. B. (2011). Addressing students with disabilities in school textbooks. Disability \& Society, 26(2), 239-242. https://doi.org/ 10.1080/09687599.2011.544063

Chiang, E. S. (2020). Disability cultural centers: How colleges can move beyond access to inclusion. Disability \& Society, 35(7), 1183-1188. https:// doi.org/10.1080/09687599.2019.1679536

Cooper, K. M., \& Brownell, S. E. (2016). Coming out in class: Challenges and benefits of active learning in a biology classroom for LGBTQIA students. CBE-Life Sciences Education, 15(3), ar37. https://doi.org/10.1187/ cbe.16-01-0074

Dunn, D. S., \& Andrews, E. E. (2015). Person-first and identity-first language: Developing psychologists' cultural competence using disability language. American Psychologist, 70(3), 255-264. https://doi.org/10.1037/ a0038636

Ernest, J. B., Reinholz, D. L., \& Shah, N. (2019). Hidden competence: Women's mathematical participation in public and private classroom spaces. Educational Studies in Mathematics, 102(2), 153-172. https://doi .org/10.1007/s10649-019-09910-w

Flink, P. (2021). Person-first \& identity-first language: Supporting students with disabilities on campus. Community College Journal of Research and Practice, 45(2), 79-85. https://doi.org/10.1080/10668926.2019.164 0147

Fox, A. M., Krings, M., \& Vierke, U. (2019). "Disability gain" and the limits of representing alternative beauty. In Liebelt, C., Böllinger, S., \& Vierke, U. (Eds.), Beauty and the norm: Debating standardization in bodily appearance (pp. 105-125). Cham, Switzerland: Springer International. https:// doi.org/10.1007/978-3-319-91174-8_5

Freeman, S., Eddy, S. L., McDonough, M., Smith, M. K., Okoroafor, N., Jordt, H., \& Wenderoth, M. P. (2014). Active learning increases student performance in science, engineering, and mathematics. Proceedings of the National Academy of Sciences USA, 111(23), 8410-8415. https://doi .org/10.1073/pnas.1319030111

Gernsbacher, M. A. (2017). Editorial perspective: The use of person-first language in scholarly writing may accentuate stigma. Journal of Child Psychology and Psychiatry, 58(7), 859-861. https://doi.org/10.1111/jcpp.12706

Gin, L. E., Guerrero, F. A., Cooper, K. M., \& Brownell, S. E. (2020). Is active learning accessible? Exploring the process of providing accommodations to students with disabilities. CBE-Life Sciences Education, 19(4), es12. https://doi.org/10.1187/cbe.20-03-0049

Jarman, M., Monaghan, L., \& Harkin, A. Q.( (2017). Barriers and belonging: Personal narratives of disability. Philadelphia, PA: Temple University Press.

Lambert, R., \& Tan, P. (2017). Conceptualizations of students with and without disabilities as mathematical problem solvers in educational research: A critical review. Education Sciences, 7(2), 51. https://doi.org/10.3390/ educsci7020051 
Lewis, T. L. (2021, January 7). January 2021 working definition of ableism Retrieved January 7, 2021, from www.talilalewis.com/blog

Martin, D. B. (2009). Researching race in mathematics education. Teachers College Record, 111(2), 295-338.

McAfee, M. (2014). The kinesiology of race. Harvard Educational Review, 84(4), 468-491. https://doi.org/10.17763/haer.84.4.u3ug18060×847412

Mingus, M. (2017, April 11). Access intimacy, interdependence and disability justice. Paul K. Longmore Lecture on Disability Studies, San Francisco, CA. Retrieved January 7, 2021, from https://leavingevidence.wordpress .com/2017/04/12/access-intimacy-interdependence-and-disability-justice/

Moorhouse, B. L. (2020). Adaptations to a face-to-face initial teacher education course "forced" online due to the COVID-19 pandemic. Journal of Education for Teaching, 46(4), 609-611. https://doi.org/10.1080/ 02607476.2020 .1755205

Mueller, C. O. (2021). "I didn't know people with disabilities could grow up to be adults": Disability history, curriculum, and identity in special education Teacher Education and Special Education, 44(3), 189-205. https://do .org/10.1177/0888406421996069

National Academy of Sciences. (2007). Beyond bias and barriers: Fulfilling the potential of women in academic science and engineering. Washington, DC: National Academies Press.

Nguyen, H.-H. D., \& Ryan, A. M. (2008). Does stereotype threat affect test performance of minorities and women? A meta-analysis of experimental evidence. Journal of Applied Psychology, 93(6), 1314-1334. https://doi org/10.1037/a0012702

Oliver, M. (2013). The social model of disability: Thirty years on. Disability \& Society, 28(7), 1024-1026. https://doi.org/10.1080/09687599.2013 818773

Padilla, A., \& Tan, P. (2019). Toward inclusive mathematics education: A metatheoretical reflection about countering ableism in mathematics standards and curriculum. International Journal of Qualitative Studies in Education 32(3), 299-322. https://doi.org/10.1080/09518398.2019.1576941

Pfeifer, M. A., Reiter, E. M., Hendrickson, M., \& Stanton, J. D. (2020). Speaking up: A model of self-advocacy for STEM undergraduates with ADHD and/ or specific learning disabilities. International Journal of STEM Education 7(1), 33. https://doi.org/10.1186/s40594-020-00233-4

President's Council of Advisors on Science and Technology. (2012). Engage to excel: Producing one million additional college graduates with degrees in science, technology, engineering, and mathematics. Washington, DC: U.S. Government Office of Science and Technology.

Reinholz, D. L., Stone-Johnstone, A., White, I., Sianez, L. M., \& Shah, N (2020). A pandemic crash course: Learning to teach equitably in synchronous online classes. CBE-Life Sciences Education, 19(4), ar60. https://doi.org/10.1187/cbe.20-06-0126

Riley, D. M. (2013). The island of other: Making space for embodiment of difference in engineering. Paper presented at: 2013 ASEE Annual Conference \& Exposition (Atlanta, GA). Retrieved January 1, 2021, from https:// peer.asee.org/the-island-of-other-making-space-for-embodiment-of -difference-in-engineering

Rose, D. (2000). Universal design for learning. Journal of Special Education Technology, 15(3), 45-49. https://doi.org/10.1177/016264340001500307

Rose, D. H., \& Meyer, A. (2002). Teaching every student in the digital age: Universal design for learning. Alexandria, VA: Association for Supervision and Curriculum Development.

Seymour, E., \& Hewitt, N. M. (1997). Talking about leaving: Why undergraduates leave the sciences. Boulder, CO: Westview.

Shah, N., Christensen, J. A., Ortiz, N. A., Nguyen, A., Byun, S., Stroupe, D., \& Reinholz, D. L. (2020). Racial hierarchy and masculine space: Participatory in/equity in computational physics classrooms. Computer Science Education, 30(3), 254-278. https://doi.org/10.1080/08993408.2020.1805285

Sins Invalid. (2019). Skin, tooth, and bone: The basis of movement is our people (2nd ed.), Berkeley, CA: Sins Invalid.

Slaton, A. E. (2013). Body? What body? Considering ability and disability in STEM disciplines. Paper presented at: 2013 ASEE Annual Conference $\&$ Exposition (Atlanta, GA). Retrieved January 1, 2021, from https://peer asee.org/body-what-body-considering-ability-and-disability-in -stem-disciplines

Stoskopf, A. (2002). Echoes of a forgotten past: Eugenics, testing, and education reform. Educational Forum, 66, 126-133.

Triano, S. (2000). categorical eligibility for special education: The enshrinement of the medical model in disability policy. Disability Studies Quarterly, 20(4), ar4. https://doi.org/10.18061/dsq.v20i4.263

Wilson, M. C., \& Scior, K. (2014). Attitudes towards individuals with disabilities as measured by the Implicit Association Test: A literature review. Research in Developmental Disabilities, 35(2), 294-321. https://doi.org/10.1016/j .ridd.2013.11.003 